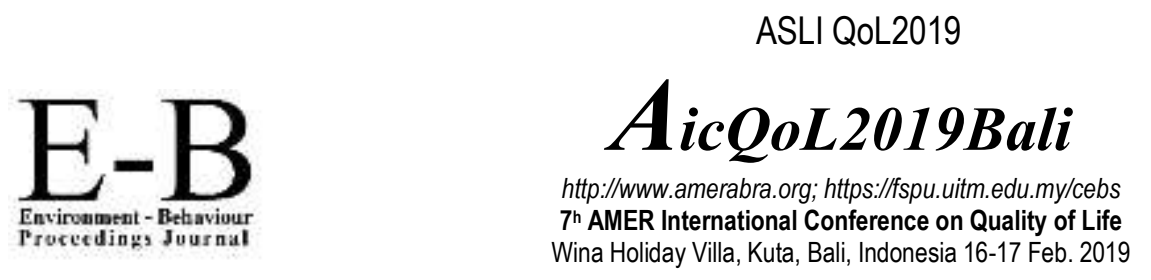

\title{
Developing a Pollution Free Environment Framework through Technology Integration (e-Hailing App)
}

\author{
Rohana Bt Sham 1, Amir 'Aatieff Bin Amir Hussin 2, Noranita Abdamia3, Marhani Mohd Anuar4 \\ 182 Logistics Department, Faculty of Business Management and Information Science, \\ 2 Information Technology, of Business Management and Information Science, \\ UCSI University, Malaysia \\ ${ }^{3}$ Economics Department, Faculty of Business Management, \\ Universiti Teknologi Mara Johor, Malaysia \\ 4 Transport Department, Faculty of Business Management, \\ Universiti Teknologi Mara, Malaysia
}

rohana@ucsiuniversity.edu.my, amir@ucsiuniversity.edu.my, noran801@johor.uitm.edu.my, honey5112@gmail.com Tel: +6012-5570602

\begin{abstract}
Cleaning the polluted river involves a considerable cost. For Baram and Miri river in Sarawak, the problem had become worst due to rapid growth. Thus, e -hailing app is proposed to reduce the problem faced. This paper will examine on the important features of the app and major function where towards the end, river pollution can be kept low with full engagement from the society. This design is in line with the 11th sustainable goals to reduce pollution. Thus, major outcome is to produce the app to reduce the amount of pollution surrounding the river in promoting a quality living.
\end{abstract}

Keywords: Sustainable Environment; e-Hailing Apps; Technology; Community Engagement

eISSN: 2398-4287 @ 2019. The Authors. Published for AMER ABRA cE-Bs by e-International Publishing House, Ltd., UK. This is an open access article under the CC BYNC-ND license (http://creativecommons.org/licenses/by-nc-nd/4.0/). Peer-review under responsibility of AMER (Association of Malaysian Environment-Behaviour Researchers), ABRA (Association of Behavioural Researchers on Asians) and cE-Bs (Centre for Environment-Behaviour Studies), Faculty of Architecture, Planning \& Surveying, Universiti Teknologi MARA, Malaysia.

DOI: https://doi.org/10.21834/e-bpj.v4i10.1614

\subsection{Introduction}

Breakneck population growth and rapid urbanization in many countries create new challenges in waste management. Annual waste generation is expected to increase by $70 \%$ from 2016 levels to around 3.40 billion tonnes in 2050 (World Bank,2018). The same report highlighted that effective waste management is often expensive and takes up to between $20 \%-50 \%$ of municipal budgets. In Malaysia, a report from the Department of Environment (2018) revealed that every year, the government spends as much as RM60 billion to clean rivers and the surrounding environment. Looking at the reality facing Malaysian rivers today, it is becoming difficult to ignore that most rivers in Malaysia had experienced a tremendous degree of river degradation leading to the destruction of the supporting ecosystem due to significant pollution and deforestation. This issue presents a considerable challenge for formulating a holistic and sustainable river basin management plan as about two-thirds of Malaysian rivers are categorized as polluted. Therefore the main aims of this study are to explore the application of smart apps that can help in the reduction of pollution in the river and the surrounding ecosystem especially for the rivers of Sarawak where the population's dependency on the river is higher compared to other states in Malaysia. The significant

eISSN: 2398-4287 @ 2019. The Authors. Published for AMER ABRA cE-Bs by e-International Publishing House, Ltd., UK. This is an open access article under the CC BYNC-ND license (http://creativecommons.org/licenses/by-nc-nd/4.0/). Peer-review under responsibility of AMER (Association of Malaysian Environment-Behaviour Researchers), ABRA (Association of Behavioural Researchers on Asians) and CE-Bs (Centre for Environment-Behaviour Studies), Faculty of Architecture, Planning \& Surveying, Universiti Teknologi MARA, Malaysia.

DOI: https://doi.org/10.21834/e-bpj.v4i10.1614 
implication of the study is to produce an intelligent app that can alert the community, engage them to assist in clearing trash from the river to help in reducing the pollution in the rivers and their surrounding areas.

\subsection{Issues of investigation}

Since billions of years ago, rivers have been the source of life for many early human civilizations (Low, Din, Chang, Moideen, \& Lee, 2018). The same research concluded that early human civilization had mainly flourished around riverbanks such as the Nile in Egypt, the Indus River valley in India and along major rivers in China. It is almost impossible to deny that rivers form a vital part of our ecosystem providing food and shelter to various organisms as well as being used a significant method of transportation by humans (Jarvie et al., 2013). Ironically, it was also reported that as human civilization progresses by leaps and bounds throughout history, the main bodies of these rivers are also affected by the enormous amount of wastes generated (Low et al., 2018). The worsening river pollution has fortunately triggered vast amounts of on water treatment technologies and materials. While various methods have been considered to combat river pollution, the most crucial element which is community engagement, is often left out. This despite possibilities that the lack of community engagement and awareness of residents in surrounding areas may have contributed towards worsening river pollution.

In Malaysia, the principal river management issues are all linked to water quality. Since $97 \%$ of Malaysia's water supply comes from rivers, poor river water quality will severely affect water supply (Chan, 2012). This is especially true for Sarawak where major cities such as Miri are connected through rivers. Miri is the second largest city in the Sarawak state of Malaysia. It is the gateway to northern Sarawak bordered by Brunei, Marudi, Bekenu and the South China Sea surrounded by the largest oil and gas reserves therefor supporting an essential part of the national economy (Anandkumar, Nagarajan, Prabakaran, \& Rajaram, 2017). Apart from the petroleum industry, the city is home to other industries such as timber processing, shipbuilding and palm oil production. Most of these industries are concentrated along the banks of the two significant Rivers (Baram and Miri Rivers) which runs through the city and finally discharged into the South China Sea. Previous researches have found that various industrial and agricultural operations in the last three decades had contributed to the high contamination of the land and marine environment in this region either directly or indirectly (Lau et al., 1996; Nagarajan et al., 2013). The situation became worst with the geographical location of the rivers where the Baram and Miri river estuaries are the final destinations for runoff water from upstream areas. This situation increases the vulnerabilities of these two rivers to pollutants (Anandkumar et al., 2017).

The most recent study on river pollution in Malaysia concluded that about two thirds its rivers to be categorized as polluted (Khalid, Mokhtar, Jalil, Rahman, \& Spray, 2018). This fact is further supported by an earlier study which highlighted that the water environment in most areas of Malaysia had suffered a certain level of pollution (Wang et al., 2017) ever since Malaysia was considered as one of the countries with a relatively high socio-economic development in Southeast Asia since 1980s.

However, to date, there has been little agreement on the method by which the entire community can be engaged in reducing river pollution. Moreover, it was found that perhaps only a few looks at the application of apps as a new method in engaging the community to free the rivers from pollution. Thus, this study was commenced with the following objectives and research question.

\subsection{Objectives of the Research}

i. To identify the current technological features needed to reduce the existing pollution level.

ii. To propose a new model of river pollution reduction utilising e-hailing applications.

\subsection{Research Question}

This research focuses on these two specific research questions.

i. What are the major technological feature and tools to be used for pollution reduction?

ii. How can e-hailing apps help to deal with the pollution levels in the rivers?

\subsection{Scope and Limitations of the Study}

The study area only covers the rivers from the state of Sarawak (Miri and Baram). The research area only focuses on two rivers namely Miri and Baram. Rivers from other state are excluded thus limiting the possibility of the findings to be generalised to other states. This paper intends to propose and develop a framework to be used for developing an app to achieve the main objectives of the research.

\subsection{Review of Literature}

This section will focus on the literature review of the environment and to factors contributing towards the pollution.

\subsection{Land Use Activities and River Pollution}

Land use is an influential factor in debris and sediment pollution in rivers. However, land use type alone is found to be an inadequate measure to explain pollutant contributions to the aquatic environment. This is because configurations within the same land use type such as land cover and development layout could also exert significant influence (Liu, Duodu, Goonetilleke, \& Ayoko, 2017). Understanding land use is essential because it acts as a reliable indicator when studying the ecological health concerning the main body of the water (Liao et al., 2017). A recent study by Rasidi et al. (2018) discovered that urban green space degradation had occurred as Malaysia moves ahead towards greater urbanization. Their research focused on Malaysia's typical urban green space where the main 
focal point was on green space management from the community on the land basis. There were no discussions on water or river pollution management resulting from the land use.

\subsection{Community Engagement Through Virtual Rewards}

One of the main pillars of this initiative is inclusiveness in encouraging community engagements towards making the tools developed through this research relevant and useful. This research intends to engage the community towards achieving Goal 11 of the U.N. Sustainable Development Goals namely having Sustainable Cities and Communities. Community participation, therefore, is essential in line with any community engagement projects. Sustainable community is an idea that has been studied in one form or another for several decades. One of the earliest studies was Ebenezer Howard's vision of Garden City dating back to the 1980s (Sharifi, 2016). There is published evidence with positive indications that modern-day communities are more open to engaging in activities contributing to community enhancements (Parker, Winston, Simpson, and Brady, 2018). Findings from that research indicated that community participation is quite encouraging. It was found that working together contributed to the success of the project by leveraging on strength and local resources of the community. A recent study by Ahmad et al. (2019) had defined green neighbourhood as the neighbourhood area which meets the needs of peoples' daily activities and allows communities to control pollution, save energy, increase employment, decrease crime rates, develop friendships, practice on-site renewable energy methods and preserve agricultural and environmentally sensitive areas. Voluntary participation through virtual rewards can be initiated by providing an e-hailing based platform.

\subsection{The Concept of e-Hailing}

E-hailing is the term commonly associated with ride sharing which involves allowing a passenger to hail nearby drivers and use their services to reach a certain destination. Implemented in the form of e-hailing apps (EHA) the platform enables users to request for transportation services based on their geo-location over the internet using integrated system to control telephone, service tracking as well as payment services (Joia \& Altieri, 2018). The concept is slightly different here. For our e-hailing app, sensors are placed in the areas where the areas where pollution occurs, one it reaches a certain level, the app will notify the community members that have the e-hailing app installed on their devices according to their geo-location thereby effectively hailing them to collect or clear the wastes or garbage. The first person to respond will be designated as the one to complete the job (just like a ride sharing e-hailing driver responding to a request of a passenger) and the one not receive the virtual reward for taking and completing the job.

\subsection{Virtual Rewards and Usage of Technology}

Studies have shown that virtual rewards which use rank-based systems to indicate members' status can be engaging as reputation conscious members of the community are highly motivated by status (Mutter, 2014). Similar research into the reward system of a crowdsourcing application also found that virtual rewards such badges and progress tracking enhances user enjoyment in the behavioural emotional and cognitive context (Goh, Pe-Than, \& Lee, 2017). These researches have shown that community engagement is possible and that a suitable rewards system can encourage sufficient community participation. Another unique feature of our research is also the proposed the community reminder function which will send reminders through the app to the participants mobile phone. Recent research conducted by Sasao, Kostakos, Kuribayashi, \& Goncalves (2017) has shown that reminders can broaden participation in local communities. This particular research also provided evidence that involving the community provides many benefits that contributed to the success of the particular project as a whole. The goal of building community awareness is to increase the community's knowledge on the current state of trash in the river and how they can help to reduce it. This is accomplished by disseminating information to the general public using various mediums including ticker boards and mobile phones. Tickers are the simpler and more economical option. They have a very simple controller inside that takes a stream of data and shift the content column by column across the display. These displays are ideal for creating an environment where users require constant movement to show live data such as sports scores, stock quotes, or headline news. They have been successfully used for disseminating information in other applications due to their advantages when compared to other digital displays such as economic cost, flexible size, simple to control (no dedicated computer needed) and seamless, smooth scrolling (Sain et al., 2017). Mobile phones, on the other hand, are the leading technology most commonly used for effective information dissemination either through push notifications (Tan et al., 2016) or traditional notifications that have been effectively used for community alerts (Toda et al., 2016). A recent study by Saffuan, Ariffin and Amin (2018) agreed that the application and design approach using green technology is a new solution that could be considered to preserve nature and swiftly reduce pollution.

\subsection{Description of Methodology}

This study uses a qualitative approach in collecting data from residents living along the river due to evidence in the literature supporting its significance in providing an in-depth perspective on the problem studied (Hartley, 2004). Stake (2010) stated that case studies are typical for the qualitative inquiry to give a better qualitative approach was seen as suitable for their research since data were collected from documents and interviews obtained from a food company. This study collects its data from two sources: reports and interviews from the Department of Environmental (DOE). Reports from the DOE refer those produced on the current state river pollution and significant activities. Additionally, interviews were also conducted with the formal authority that administers all the rivers in Sarawak which includes Lembaga Sungai-Sungai Sarawak, the Department of Irrigation and Drainage of Sarawak as well as the Miri City Council. The interviews provide a better view of the current problem and which could help in adding essential features to the app derived from the collected feedback. Also, interview sessions held with the heads of villages located around the river under study together with ten 
villagers living along the river gauge the readiness of the community in engaging on the issue of pollution in the surrounding areas. The interview sessions are aimed at uncovering the significant factors and the primary source that lead to river pollution along with the challenges faced in implementing the smart trash app into the tool to be used as a step towards reducing the pollution level. The data was analysed with a manual coding process as suggested by Strauss and Corbin (1998) using open coding and axial coding. Open coding specifies categorizing data obtained from the interviewees based on phrases or sentences used into tentative labels. Axial coding, on the other hand, involves grouping the tentative labels to create themes or categories. Coding makes it easier to explore the data for making comparisons and to identify any patterns that require further investigation. This is one of the primary motivations for this study to adopt the same approach.

\subsection{Reliability, Validity and Triangulation of Data}

In ensuring the quality of data obtained from the reports and interviews are reliable and valid, data triangulation was conducted. Cohen and Manion (2000) defines triangulation as an attempt to map out, or explain more fully, the richness and complexity of human behaviour by studying it from more than one standpoint. Likewise, Denzin (2009) states that performing data triangulation for validation involves using different sources of information to increase the validity of a study. This study adopted a similar approach to validate the research data as suggested by Denzin (1997).

\subsection{Findings}

The main finding for this study is the development of an app that is designed to help reduce pollution through by leveraging on the community engagement method. With a new concept of notification and virtual rewards to motivate in reducing pollution and cleaning the environment, all members of the community can easily download the app to get notified when the amount of garbage reaches a predefined critical level.

\subsection{Findings on the current technology features required}

\section{i. Camera and Weight sensor}

The usage of camera and corresponding sensors which are connected to the monitoring device revolutionised a new way of cleaning the environment where the sensors can be placed anywhere to alert the community to work together in creating a clean and healthy living for the whole society. For testing purposes, the small-scale implementation was built using off-the-shelf Arduino components using Arduino UNO Wi-Fi based on the ATmega328P with an ESP8266 WiFi Module integrated as the base controller connected to a Load Cell to measure weight and an OV7670 camera for imaging. The weight sensor is used indicate that it is time to collect while the camera is only used for verification. The collected data is then used to send push notification through an alert system to 'hail' the user to collect the garbage and earn a virtual reward.

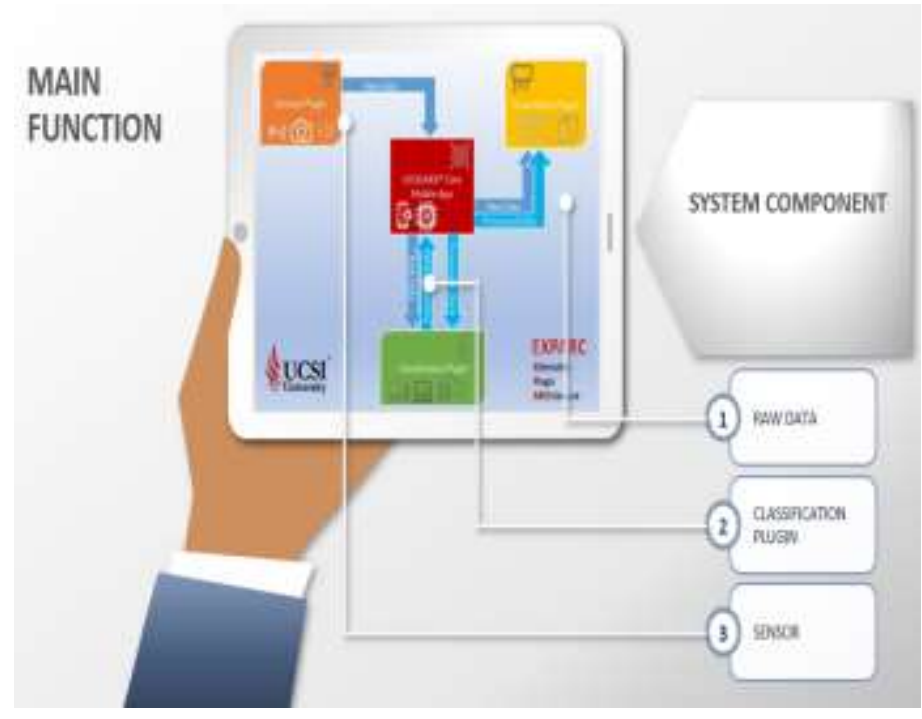

Fig. 2: System Components for the e-hailing Trash App

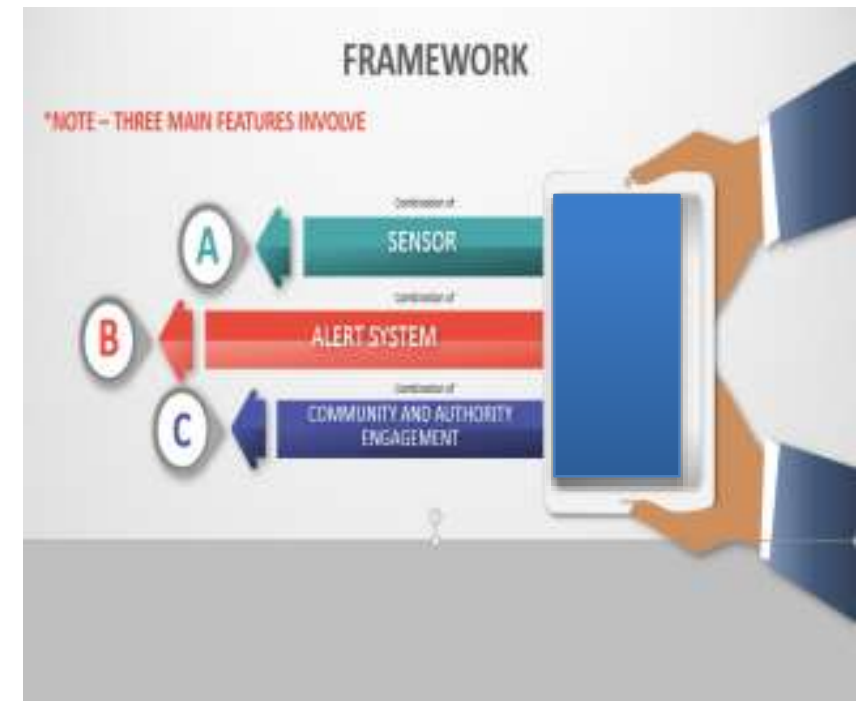

Fig. 3: Main Framework for the e-hailing Trash App 


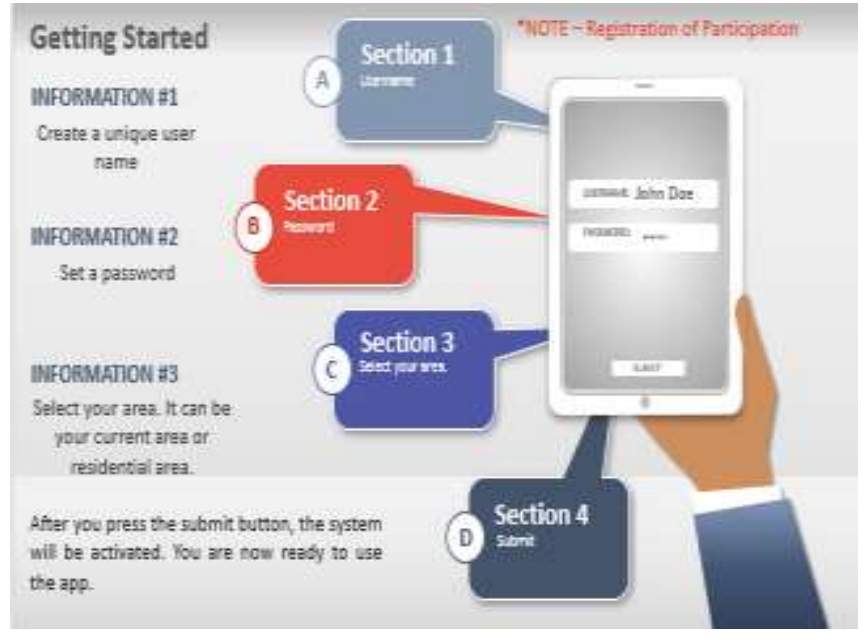

Fig. 4: Getting Started with e-hailing Trash App

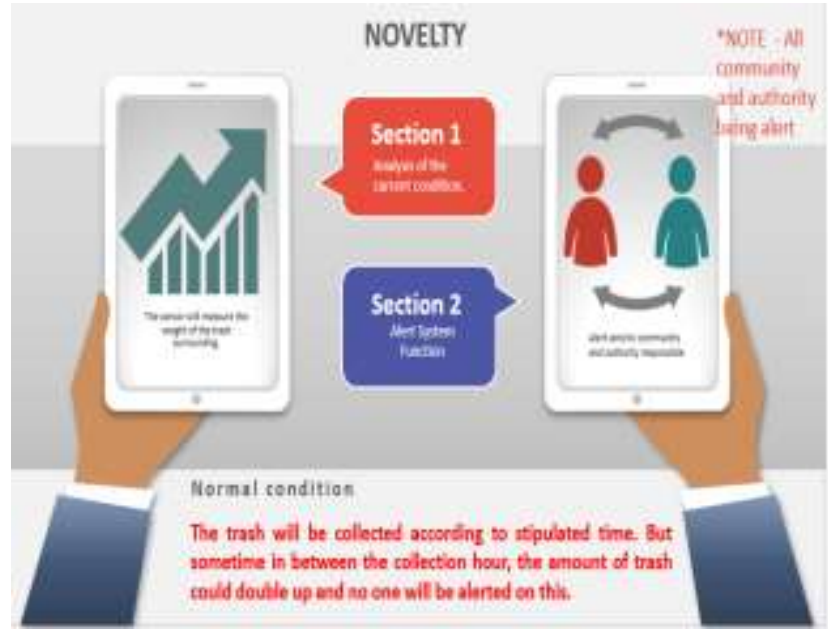

Fig. 5: Novelty of the e-hailing App

The main system component of the app starts with reading raw data. This is followed by the engagement of a classification plugin that will be used to determine the different types of garbage or trash. Finally, the sensor will detect other attributes of the trash such as weight or dimensions then sends an alert to all users if the current level of garbage is to be collected. The concept of e-hailing is chosen because the community now had an option to turn the trash into cash anytime, they want. This will reduce the problem faced by the existing river cleaning schedule and garbage collection system due to an anytime garbage collection routine.

ii. Functions of e-hailing apps and pollution level reduction process.

By following a few simple steps, the community can now become a part of the environment cleaning team at their fingertips. A novelty of the app is the sensor that is capable of operating 24 hours and generating an alert on the current garbage trapped in the river and the surrounding areas especially in between of the garbage collection scheduled time or cleaning time. This app can easily be download for free, and the registration can be completed by following the four simple steps as shown in Fig 4.

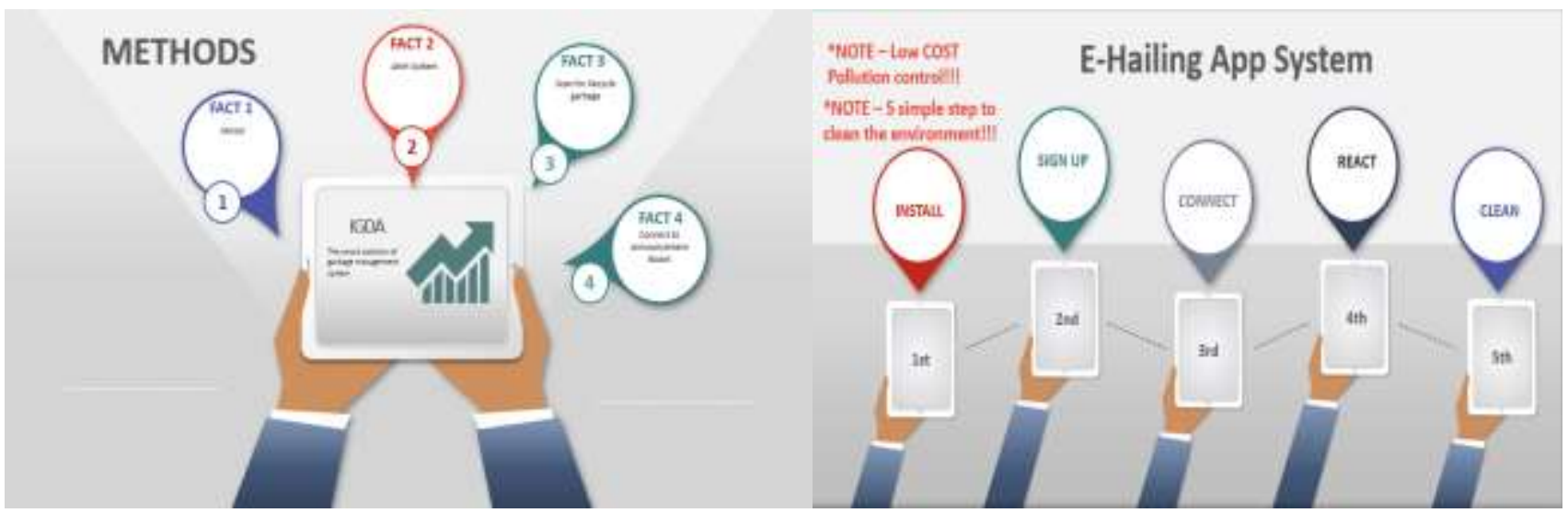

Fig. 6: Main Method with e-hailing Trash App

Fig 7: E-hailing App System

With the current camera and suitable sensors attached to monitor nearby polluted areas, the trash can be turned into cash by the surrounding community. This can be either incentive received from recycling or through the virtual reward system built into the app. As the e-hailing app is free, this indirectly translates into cost savings of cleaning the environment, provided full support is received from the community living in the surrounding areas. The function of scanning and segregating recyclable wastes from other garbage is a new method to encourage the community engagement by incentivising them with the possibility of making money from the trash while helping to clean the environment.

\subsection{Discussion}

It is believed that with the introduction of the app, tangible benefits can be gained by the environment. It is hoped that the app will encourage the community to engage in the activities so that the river could be clean up in a better way and status alerts of the improvements to the river after the cleaning process could be sent to all the community members. By using the smart e-hailing app, the environment can be kept clean all the time at almost zero cost. With the installation of the app, the garbage problems in these rivers can be monitored easily with little or no human intervention. Consequently, the corresponding sensors can also be installed at any location. 
This could help in creating a virtual link bridging all members of the community with the opportunity to get involved in cleaning up the environment especially if the location is nearby their residential area where the recycled item could be used to generate income.

\subsection{Conclusion and Recommendation}

It can be concluded that by using the e-hailing app, the level of pollution level in the rivers and the surrounding areas could be reduced at the lowest possible cost. Moreover, the usage of this app could also be used to generate economic among the lower income group or current recycle practitioner where trash could be converted into cash anytime. Concerning a recommendation for future work, this app should be expanded and deployed worldwide as the central tool for facilitating in the cleaning up the environment. It should also not be limited to applications for the river and its surrounding areas but other applications as well. The app is easy to use, and the usage is free of charge.

\section{Acknowledgements}

We want to thank all respondents and government officers from the Department of Environment and Department of Statistics for the data provided to proceed with the study.

\section{References}

Ahmad, P., Misni, A., Kamaruddin, S.M \& Daud, N., (2019). A Conceptual Review Of Green Neighbourhood Adaptive Model For Urban Living. Asian Journal Of Behavioral Studies,4(15), 1-9.

Anandkumar, A., Nagarajan, R., Prabakaran, K., \& Rajaram, R. (2017). Trace metal dynamics and risk assessment in the commercially important marine shrimp species collected from the Miri coast, Sarawak, East Malaysia. Regional Studies in Marine Science. 16, 79-88.

Borhan, H., \& Ahmed, E. M. (2012). Green Environment: Assessment of Income and Water Pollution in Malaysia. Procedia - Social and Behavioral Sciences, 42(July 2010), 166-174.

Chan, N. W. (2012). Managing Urban Rivers and Water Quality in Malaysia for Sustainable Water Resources. International Journal of Water Resources Development, 28(2), 343-354.

Cohen, L. \& Manion, L.(2000). Research methods in education. British Journal of Educational Studies. 48 (4):446-446.

Denzin N. K. (1997). Interpretive ethnography: Ethnographic Practices for the 21st Century. Thousand Oaks, CA: Sage.

Denzin N. K. (2009). On Understanding Emotion. New Brunswick, NJ: Transaction Publishers.

Department of Environment (2018) Environment Quality (Clean Air) Regulation 2014- Environmental Quality Act 1974, Department of Environment, Ministry of Energy, Technology, Science, Environment \& Climate Change.

Goh, D. H., Pe-Than, E. P., \& Lee, C. S. (2017). Perceptions of virtual reward systems in crowdsourcing games. Computers in Human Behavior, 70, 365-374. Hartley, J. (2004). Case studies in organizational research. Qualitative Methods in Organizational Research: A Practical Guide. pp.208-229. London: Sage. Jarvie, H.P., Sharpley, A.N., Withers, P.J., Scott, J.T., Haggard, B.E., \& Neal, C.(2013). Phosphorus Mitigation To Control River Eutrophication: Murky Waters, Inconvenient Truths, And Postnormal Science. Journal Environment Quality. 42 (2), 295-304.

Joia, L. A., \& Altieri, D. (2018). Antecedents of continued use intention of e-hailing apps from the passengers' perspective. The Journal of High Technology Management Research, 29(2), 204-215.

Khalid, R. M., Mokhtar, M. Bin, Jalil, F., Rahman, S. A., \& Spray, C. (2018). Legal framing for achieving 'good ecological status' for Malaysian rivers: Are there lessons to be learned from the EU Water Framework Directive? Ecosystem Services, 29(August 2017), 251-259

Lau, S., Mohamed, M., \& Su'ut, S. (1996). Logru Berat Di Dalam Sedimen Sebagai Penyurih Kepada Punca Pencemaran Sungai Sarawak. Malaysian J. Anal. Sci. 2, 365-371.

Liao, J., Chen, J., Ru, X., Chen, J., \& Wei, C. (2017). Heavy metals in river surface sedi- ments affected with multiple pollution sources, South China: distribution, enrichment and source apportionment. J. Geochem. Explor. 176, 9e19.

Liu, A., Duodu, G. O., Goonetilleke, A., \& Ayoko, G. A. (2017). Influence of land use configurations on river sediment pollution. Environmental Pollution, $229,639-646$.

Low, W. P., Din, M. F. M., Chang, F. L., Moideen, S. N. F. B., \& Lee, Y. Y. (2018). Empirical Models Of Kinetic Rate For River Treatment Analysis Of Cellulosic Materials. Journal of Water Process Engineering. 23(September 2018), 257-264.

Mutter, T. (2014). Don't take away my status!-Evidence from the restructuring of a virtual reward system. Computer Networks(75), 477-490.

Parker, C. J., Winston III, W., Simpson, T., \& Brady, S. S. (2018). Community Readiness to Adopt the Communities That Care Prevention System in an Urban Setting. American Journal of Preventive Medicine, 55(5), S59-S69.

Rasidi, M.H., Jamirsah, N.,\& Said, I., (2018). Development of Urban Green Space Affects Neighbourhood Community Social Interaction. Asian Journal of Environment Behaviour Studies, 3(80),71-88.

Saffuan, R., Ariffin, J., \& Amin, Z., (2018).Green Technology Design Approach for Liveable Park of Tasik Biru Kundang, Malaysian. Asian Journal of Environment Behaviour Studies, 3(7), 91. 
Sain, V., Kundu K.K., \& Mehta, V.P. (2017). Dissemination and Utilization of Market Information System by Farmers for Gram Crop in Bhiwani District of Haryana, India. International Journal Current Microbiology Application Science, 6(4),58-65

Sasao, T. K., Kostakos, V., Kuribayashi, K., \& Goncalves, J. (2017). Community Reminder: Participatory contextual reminder environments for local communities. International Journal of Human-Computer Studies,(102), 41-53.

Sharifi, A. (2016). From Garden City to Eco-urbanism: The quest for sustainable neighbourhood development. Sustainable Cities and Society, 20(1-16).

Stake, R.K. (2010). Qualitative Research: Studying How Things Work. New York: The Guilford Press

Strauss, A. \& Corbin, J.M. (1998). Basics of Qualitative Research: Techniques and Procedures for Developing Grounded Theory. California: SAGE Publications. Cohen and Manion (2000)

Tan, L., Roegiest, A., Lin, J., \& Clarke, C. L. (2016). An exploration of evaluation metrics for mobile push notifications. In Proceedings of the 39th International ACM SIGIR conference on Research and Development in Information Retrieval (pp. 741-744). ACM.

Toda, M., Njeru, I., Zurovac, D., Tipo, S. O., Kareko, D., Mwau, M., \& Morita, K. (2016). Effectiveness of a mobile short-message-service-based disease outbreak alert system in Kenya. Emerging infectious diseases, 22(4), 711.

Wang, A. J., Bong, C. W., Xu, Y. H., Hassan, M. H. A., Ye, X., Bakar, A. F. A. \& Loh, K. H. (2017). Assessment of heavy metal pollution in surficial sediments from a tropical river-estuary-shelf system: A case study of Kelantan River, Malaysia. Marine Pollution Bulletin, 125(1-2), 492-500.

World Bank Development Report (2018), Reducing Pollution. The World Bank Group. 